\title{
Correction to: Comparative study of HDMRs and other popular metamodeling techniques for high dimensional problems
}

\author{
Liming Chen ${ }^{1,2} \cdot$ Hu Wang ${ }^{1,2}$ (D) Fan $\mathrm{Ye}^{1,2} \cdot$ Wei $\mathrm{Hu}^{1,2}$
}

Published online: 24 August 2018

(C) Springer-Verlag GmbH Germany, part of Springer Nature 2018

\section{Correction to: Structural and Multidisciplinary Optimization \\ https://doi.org/10.1007/s00158-018-2046-8}

The original version of this article unfortunately contains 2 mistakes. The authors wish to revise the mistaken figures (Fig. 15(b), Fig. 17(a), Fig. 17(b), Fig. 18(a), and Fig. 18(b)) and a mistaken description of the article to improve their work, see below corrections.

Location 1: Appendix 3: Variability in performance of metamodels with multiple sampling strategies.

Revise Fig. 15(b), Fig. 17(a), Fig. 17(b), Fig. 18(a) and Fig. 18(b) as follows:

The online version of the original article can be found at https://doi.org/ 10.1007/s00158-018-2046-8

Hu Wang

wanghu@hnu.edu.cn

1 State Key Laboratory of Advanced Design and Manufacturing for Vehicle Body, Hunan University, Changsha, China

2 Joint Center for Intelligent New Energy Vehicle, Shanghai, China 


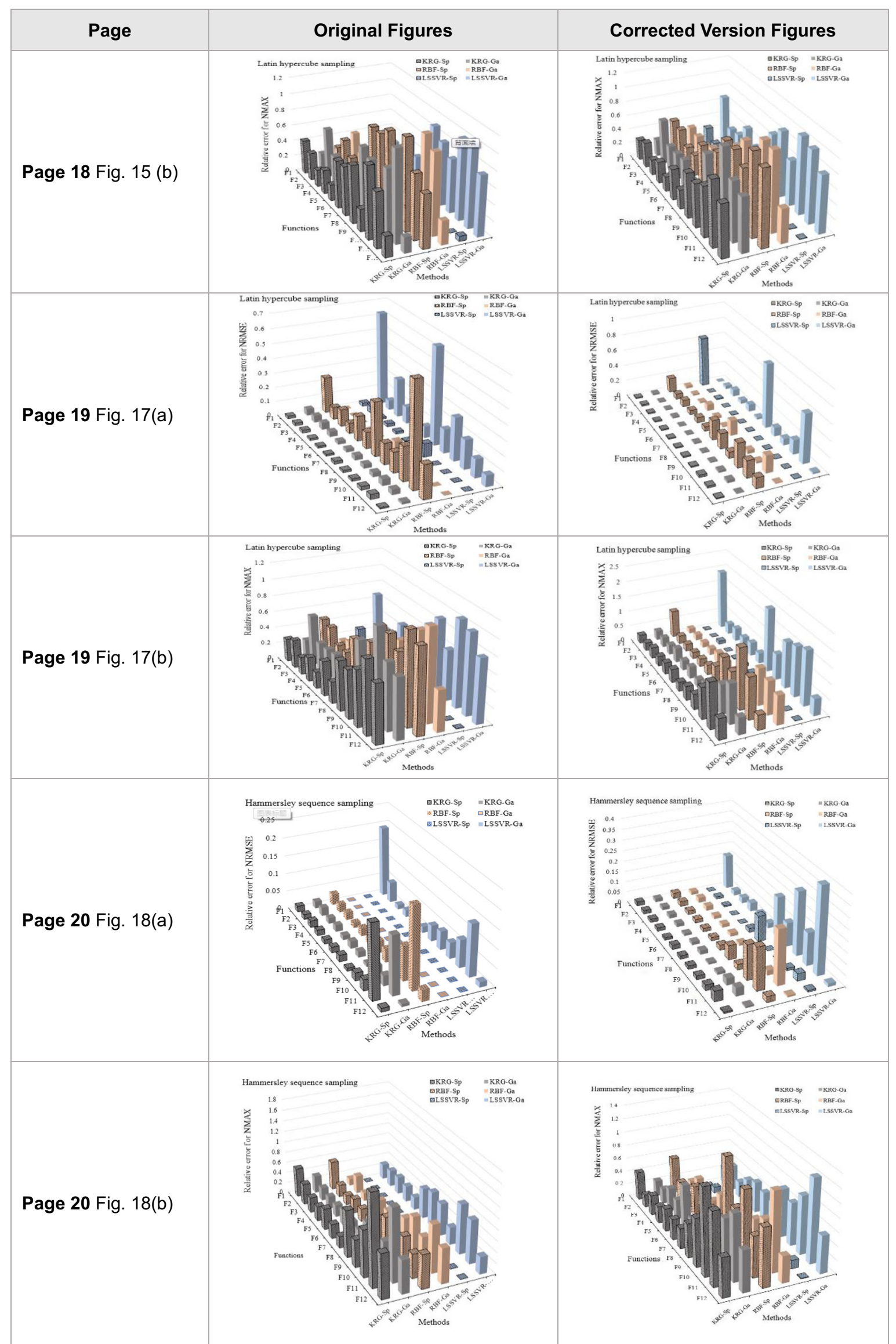


Location 2: 4.2 Comparison among cut-HDMR methods.

Revise the description of "L-H" and "LSSVR-HDMR" in page 13 as follows:

Page

Page 13
Original Language (See highlight)

... and "L-H" indicates LSSVR-HDMR.
Corrected Version Language ... and "S-H" indicates SVR-HDMR.

The original article has been corrected. 